\title{
Damage Evolution and Mechanical Characteristics of Porous Rock Under Uniaxial Cyclic Impact Loads
}

\author{
Nan $\mathrm{Hu}^{1}$, Changhong $\mathrm{Li}^{1, *}$, BODA Eric $^{2}$, Chen Qiao $^{1}$ and Yonggang Xiao ${ }^{1}$

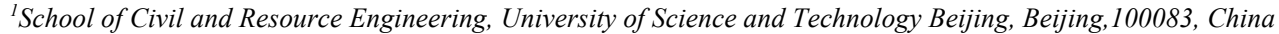 \\ ${ }^{2}$ KC Engineering, Gasabo district, Kigali, K324, Rwanda
}

Received 12 December 2020; Accepted 26 February 2021

\begin{abstract}
Cyclic impact loads accompany the process of blasting mining of metal mines. The influence of impact on the strength of surrounding rock is evidently different due to the nature of surrounding rock and the strength of impact. A test method using rectangular stress waves to carry out multiple impact strength cyclic loading was proposed to reveal the evolution characteristics of stress and strain and the crack propagation process of porous rocks under cyclic impact loading. The large-diameter split Hopkinson pressure bar device (SHPB) was employed to conduct constant amplitude cyclic impact tests under three accelerated air pressure conditions of $0.09,0.12$, and $0.16 \mathrm{MPa}$ and a single impact failure under accelerated air pressure of $0.20 \mathrm{MPa}$ test. The stress wave signals in the incident rod and exit rod in the process were collected. The "three-wave method" was used for processing, and the stress-strain curve of the rock specimen was obtained. The failure process of crack formation, propagation, and penetration in the specimen was analyzed from the perspective of damage mechanics. Results show that during the low-strength multicycle impact of $0.09,0.12$, and 0.16 MPa accelerated air pressure, the granite specimens mainly fracture along the impact axis. The stress-strain curve of porous granite has an evident constant stress stage, which is approximately $110 \mathrm{MPa}$ and does not change with the impact load. The cyclic impact failure process is mainly divided into the compaction of the original crack and the growth of the new crack. The compaction of the crack has a certain increase in the impact strength of the rock. The expansion of new cracks has no evident influence on the axial strength, causing an increase in the peak stress as the impact process progresses. This study provides a reference for damage characteristics and evolution process of polyporous granite under cyclic impact load.
\end{abstract}

Keywords: cyclic impact, SHPB, granite, constant stress

\section{Introduction}

Blasting technology has been widely used in the mining process of metal mines due to its high production efficiency and low construction difficulty [1]. At the same time, while the blasting action breaks the target ore body, it forms an impact-type dynamic load in a larger area [2]. Under the action of multiple blasting, the cyclic impact dynamic load causes the accumulation of damage to the surrounding rock mass and even leads to unstable and damaged surrounding rock [3]. Frequent impacts have caused rock mass damage, and accidents are common in tunnel engineering, water conservancy, and hydropower projects.

However, the damage process and damage degree of rocks are affected by many factors. For example, the strength, loading method, and loading waveform of the cyclic impact load are different. The lithology, temperature, porosity, and water content of the rock are also different. The depth of the surrounding rock and the different stress environment affect the peak impact strength and the damage during the damage process. Dissipation of energy and damage patterns of rocks exhibit evident differences.

On this basis, scholars have conducted substantial studies on the loading method and analysis method of cyclic

*E-mail address: Ich_ustb@163.com

ISSN: 1791-2377 @ 2021 School of Science, IHU. All rights reserved. doi:10.25103/jestr.141.12 impact load [4-7]. However, blind spots are still found in the existing results; they are relatively few especially on the direction of response characteristics of rock under squarewave impact load. On this basis, the split Hopkinson pressure bar device (SHPB) is used to apply a rectangular stress wave type cyclic impact load to the specimen. The waveform data are collected from the incident rod and the transmission rod in the process, and the three-wave method is used for the analysis. It aims to provide a reference for the damage and failure characteristics of rocks under typical rectangular stress wave impact loads.

\section{State of the art}

Scholars from various countries have conducted substantial studies on the mechanical characteristics of rock under impact load. Xu et al. [8] used a parallel bond model (PBM) to simulate the SHPB impact test of a rock semidisc and obtained the dynamic fracture toughness characteristics of rock materials. However, due to the single geometric form of the sphere model and the simple force transmission between crystals, phenomena, such as high tensile-compression strength ratio and low internal friction angle, appear in the macrocalibration of the material. Li et al. [9] carried out dynamic impact tests on limestone, dolomite, and sandstone, and then combined with the crystal dispersion method to 
Nan Hu, Changhong Li, BODA Eric,Chen Qiao and Yonggang Xiao/

Journal of Engineering Science and Technology Review 14 (1) (2021) 107 - 113

analyze the high-strain rate mechanical and damage characteristics of the material. However, they lacked a detailed description of the crack propagation process. By studying the energy absorption process in the impact process, Gan et al. [10] found that the energy absorption efficiency of magnetite ore increased initially and then stabilized with the increase in incident energy. However, they did not establish corresponding relationship between the energy dissipation and rock damage process. Liu et al. [11] discussed the influence of joint parameters and load strain rate on the dynamic mechanical properties of rock masses, but insufficient consideration was provided to the changes in various parameters as the impact proceeded. Zhang et al. [12] obtained the energy evolution and transformation law in the damage process through uniaxial cyclic loading and unloading experiments on red sandstone specimens, which were affected by the loading rate of equipment. However, they failed to involve the energy evolution law under higher loading rate. Zhang Fan et al. [13] analyzed the compressive strength, elastic modulus, and other mechanical properties of rock based on the test data. They found that the mechanical properties of rocks were closely related to the mineral composition and microstructure, but the crack propagation on a larger scale could not be described. Lv et al. [14] analyzed the relationship between the cumulative specific energy absorption value of sandstone under impact load cycles and the incident energy, damage degree, and other parameters. However, less attention was provided to the mechanical response of rocks.

Gatelier et al. [15] carried out quasistatic uniaxial and triaxial cyclic loading tests on porous sandstone to analyze the influence of anisotropy on material prepeak damage. However, due to its smaller load strength than the impact load and longer duration, its strength characteristics were relatively different from those under impact conditions. Through the analysis of a large amount of engineering data, MN Bagde and V. Petros [16] found that most rock failures were not caused by a single impact load but of fatigue failure under the action of cyclic impact load. However, the actual situation in engineering was more complicated and failed to conduct in-depth analysis on the specific destruction process. D. Gregoire et al. [17] found the temporary stop and cracking phenomenon in the prefabricated crack propagation process under impact load. However, the study on the entire process of crack development was limited. K. RaviChandar and WG Knauss [18] proposed that crack arrest was a sudden phenomenon. When a crack arrest occurred, the stress intensity factor during the arrest was much smaller than the intensity factor during the initiation of the crack tip. Their work focused on the initiation mechanism of a single crack, and the fracture failure of rock was often the result of the propagation and penetration of multiple cracks. M. Ghamgosar et al. [19-20] studied the microscopic fracture mechanism of rocks by static and cyclic loading methods, but the study on the mechanical characteristics and evolution of stress and strain in different loading methods was insufficient. N. Erarsln [21] used the detailed observation of electron microscope to detect the microscopic dominant mechanism of rock crack propagation, and the influence factors involved in the macroscopic damage of rock were more complicated. A. Malika et al. [22-23] obtained the rule that the dynamic characteristics of basalt were affected by the impact strain rate. They found that the deformation modulus, impact strength, and fracture energy increase with the increase in impact strain rate. However, they failed to consider the dynamic characteristics under different impact strengths.

In summary, the existing studies mainly focus on two directions. The first direction includes the characteristics and evolution of mechanical parameters, such as stress, strain, elastic modulus, and strength of rock under cyclic loading. The second direction is the combination of the energy perspective, the energy dissipation, and absorption process in the cyclic impact process with the rock damage process. At present, detailed work on the process of the initial damage core, the expansion of the crack, and the penetration of the crack in the original crack in the specimen during the cyclic impact is limited. The SHPB device is used to carry out the cyclic impact test of the rectangular stress waves on the granite under different impact strength. Through the analysis of the stress and strain characteristics in the process, the evolution process of internal cracks during the damage process of the specimen and the law of influence on rock strength are analyzed.

The remainder of this study is organized as follows. The third section describes the specimen preparation and test process of Hopkinson test. The fourth section analyzes the stress-strain characteristics and evolution laws of granite specimens during cyclic impact. The last section summarizes the conclusions.

\section{Methodology}

\subsection{Sample preparation}

The granite sample used in this test was taken from the deep $-960 \mathrm{~m}$ of Sanshandao Gold Mine in Laizhou City, Shandong Province. After the uniaxial compression test, the average uniaxial compressive strength of the sample is $88.3 \mathrm{MPa}$, the Poisson's ratio is 0.202 , and the average elastic modulus is $37.656 \mathrm{GPa}$. The granite sample was cut after core drilling with water drill to make a disc-shaped specimen of $\Phi 50$ $\mathrm{mm} \times 25 \mathrm{~mm}$, as shown in Fig. 1 and Fig. 2. In order to avoid stress concentration caused by biased pressure during the processing of the rock sample, the unevenness of the specimen is controlled within $0.02 \mathrm{~mm}$. The void ratio of the test piece is relatively large, and the uniformly distributed, irregular original damage cavity can be seen on the surface of the test piece, and the maximum diameter is about $1 \mathrm{~mm}$. Based on this, it is inferred that there are similar original damage structures evenly distributed inside the specimen.

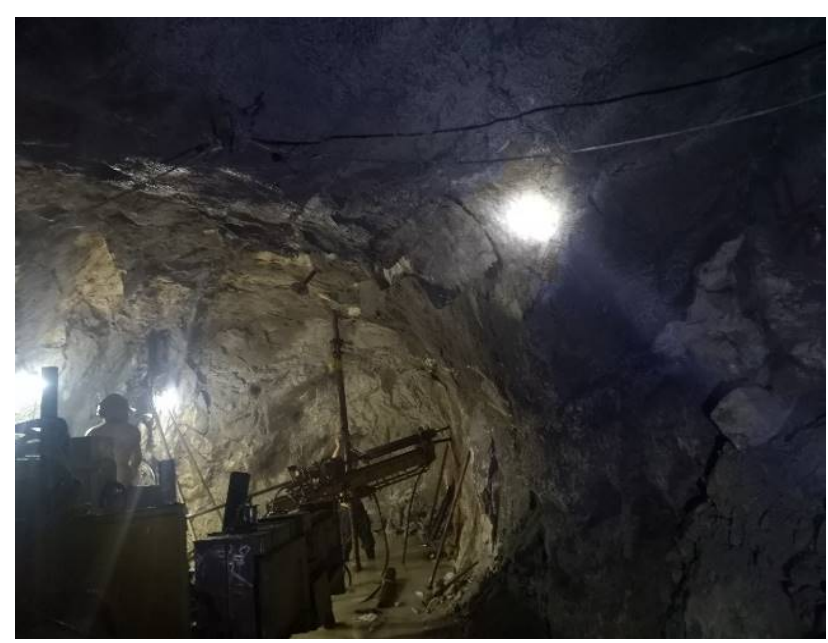

Fig. 1. Site drilling sampling 
Nan Hu, Changhong Li, BODA Eric,Chen Qiao and Yonggang Xiao/

Journal of Engineering Science and Technology Review 14 (1) (2021) 107 - 113

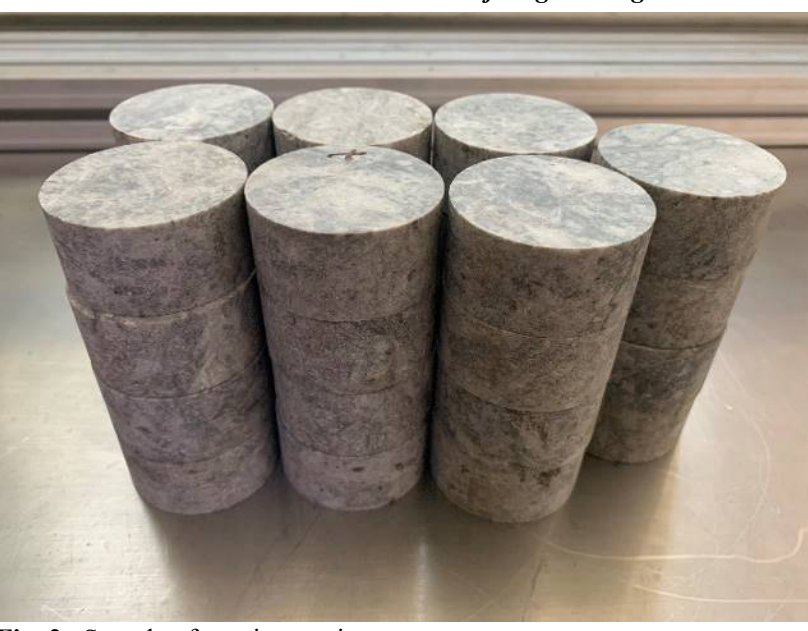

Fig. 2. Sample of granite specimen

\subsection{Test principle}

The impact test uses an improved large-diameter $(50 \mathrm{~mm}$ diameter) SHPB device. During the test, the bullet hits the incident rod to form a compressed pulse. When this pulse propagates to the interface between the steel rod and the rock specimen, part of the pulse is reflected back to the incident rod, and the other part continues to propagate in the original direction, forming a transmission pulse in the transmission rod. The whole process is measured by the strain gauges attached to the incident rod and transmission rod. According to the one-dimensional stress wave theory, the "three-wave method" formula suitable for brittle materials is selected to process the signal, and the stress, strain and strain rate calculation formulas can be obtained:

$$
\begin{aligned}
& \dot{\varepsilon}(t)=\frac{c}{l_{s}}\left(\varepsilon_{i}(t)-\varepsilon_{r}(t)-\varepsilon_{t}(t)\right) \\
& \varepsilon(t)=\frac{c}{l_{s}} \int_{0}^{t}\left(\varepsilon_{i}(t)-\varepsilon_{r}(t)-\varepsilon_{t}(t)\right) d t \\
& \sigma(t)=\frac{A_{e} E}{2 A_{s}}\left(\varepsilon_{i}(t)+\varepsilon_{r}(t)+\varepsilon_{t}(t)\right)
\end{aligned}
$$

Where: $\dot{\varepsilon}(t)$ is the average strain rate of the specimen, $\varepsilon(t)$ is the average strain, $\sigma(t)$ is the average value of the stresses at both ends, $\varepsilon_{i}(t)$ is the measured incident wave, $\varepsilon_{r}(t)$ is the measured reflected wave, $\varepsilon_{t}(t)$ is the measured transmitted wave, $A_{e}$ and $A_{s}$ respectively represent the crosssectional area of the pressure rod and the specimen, $E$ and $c$ are the elastic modulus and longitudinal wave velocity of the compression rod, $l_{s}$ is the length of the specimen.

\subsection{Test plan}

During the test, the specimens were loaded with single impact and cyclic impact. By adjusting the size of the accelerating air pressure, different impact load strengths can be obtained. In order to obtain a suitable accelerating air pressure, the sample is first subjected to a pre-impact test, and the critical accelerating air pressure required for the rupture of the test piece is about $0.18 \mathrm{MPa}$. Set the air pressure for a single impact test to $0.2 \mathrm{MPa}$. The air pressure of the cyclic impact test is set to $0.09 \mathrm{MPa}, 012 \mathrm{MPa}$, and $0.16 \mathrm{MPa}$. During the test, the accelerating air pressure is kept constant, and the specimen is subjected to cyclic impact until the specimen ruptures. Fig. 3 shows the split Hopkinson pressure bar device.

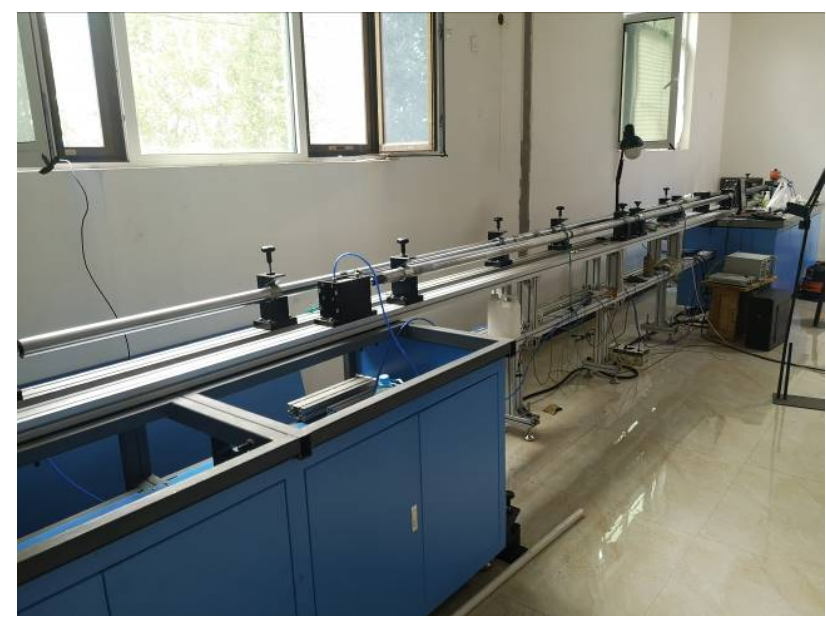

Fig. 3. Large-diameter split Hopkinson pressure bar system

\section{Result Analysis and Discussion}

Based on the one-dimensional stress wave theory in 3.2 and the experimental data in 3.3 , this study obtains the evolution process of the stress and strain of the specimen during the impact process and analyzes the data in combination with the damage mechanics theory.

\subsection{Typical stress and strain characteristics}

Fig. 4 shows the typical half stress-strain curve (the third impact) of the A1 specimen during the cyclic impact under the accelerated air pressure of $0.09 \mathrm{MPa}$. During the impact process, the change trend of the stress-strain curve is similar and can be roughly divided into three stages.

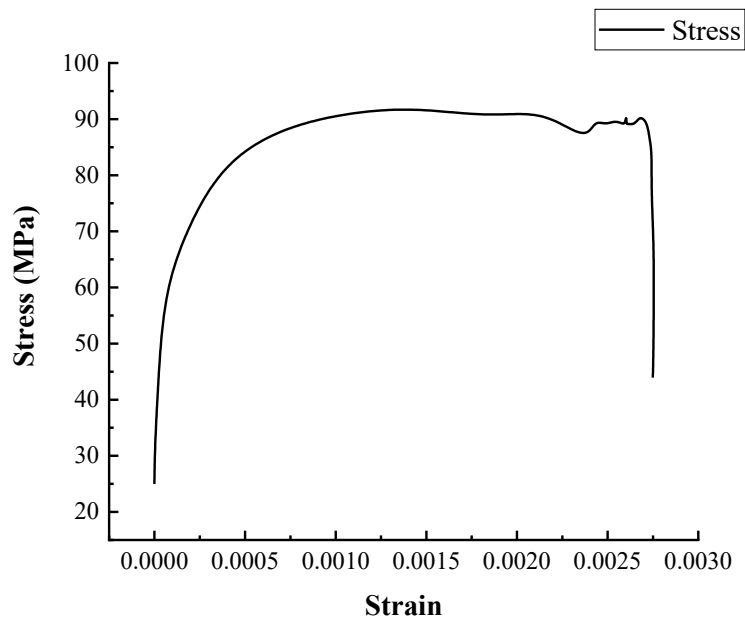

Fig. 4. Typical stress-strain curve during cyclic impact

In the first stage, at the beginning of the impact load, there is an approximately straight section, which is relatively short and is an elastic stage. In the second stage, the curve enters the nonlinear deformation stage and the slope of the curve gradually decreases. In the third stage, when the stress peak is reached, the stress It did not drop immediately, but remained constant, and the strain continued to increase, forming an obvious constant stress stage. The stress dropped rapidly in the subsequent rebound stage, and the data became invalid. 
Nan Hu, Changhong Li, BODA Eric,Chen Qiao and Yonggang Xiao/

\section{Journal of Engineering Science and Technology Review 14 (1) (2021) 107 - 113}

It is analyzed that due to the large void ratio inside the specimen, the normal tensile stress in the specimen reaches the threshold of crack propagation during the constant stress stage, causing the crack to break and the direction of the crack is axial. In the process of crack opening, the strain increases continuously and the axial stress remains unchanged. Stress concentration areas are formed at both ends of the crack, which causes the crack to continue to expand in the axial direction.

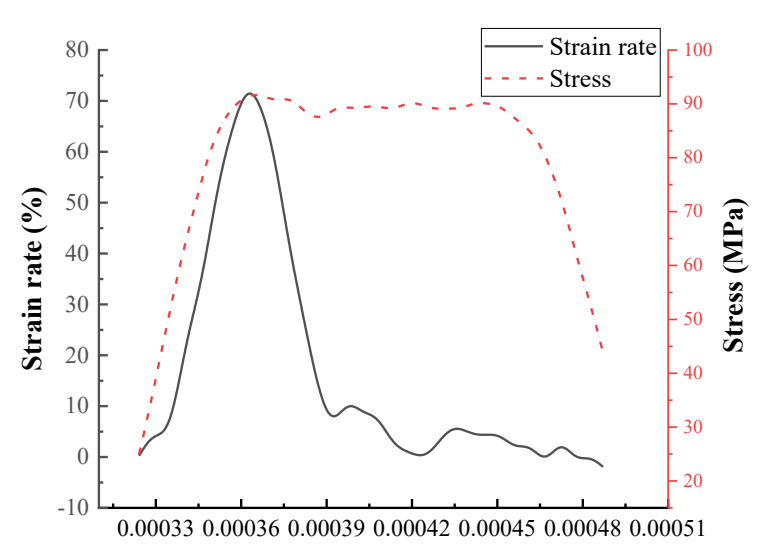

Time (S)

Fig. 5. Strain rate-stress-time diagram

The change rule of strain rate with time is shown in Fig. 5 As the stress in the elastic stage increases, the strain rate increases rapidly, and both peaks appear at the same time, which is also in line with the stress-strain rule in the elastic stage. Subsequently, the stress remains stable and the strain rate drops rapidly. During this process, the cracks rapidly expand and the incident energy is converted into the surface energy of the new cracks. Then the number of activated cracks decreases, and the constant stress continues to remain unchanged, showing a certain hysteresis.

\subsection{Stress and strain characteristics of specimens under cyclic impact loading}

Fig. 6-Fig. 9 shows the stress-strain curve of the sample under different impact loads, among which Figure 6-Figure 8 is the cyclic impact load test, and Figure 9 is the single impact failure test. Define the maximum stress of the loading section as the peak stress, and the strain value obtained before the data failure is the maximum strain.

The stress-strain situation of the A1 specimen under the accelerated air pressure of $0.09 \mathrm{MPa}$ is shown in Fig. 6. As the number of impacts increases, the plasticity of the granite specimens increases during the impact.

The curve trend of the first two impact processes is similar, the maximum stress value is small, about 90MPa. The maximum strain value is obviously smaller, about 0.0027 , and the stress constant stage is obvious. From the 3 rd to the 5 th impact, the curve showed a linear-nonlinearlinear change trend, the maximum stress and maximum strain increased, and there was no obvious constant stress stage. During the 6th to 8th impact, the constant stress stage reappeared, and the maximum stress and maximum strain were similar to the $3-5$ th.

As far as the entire impact process is concerned, due to the low impact strength, the differentiation of the original void compaction stage of damage evolution, damage nucleus formation stage, crack propagation, and crack penetration stage is more obvious.

The first is the compacting stage of the original pores: during the first two impacts, the compacting effect of the original pores is obvious. When the stress reaches its peak, the void collapse causes a short unloading process, causing the stress to not increase further. The crack has not been fully developed, the damage degree of the specimen is small, and the maximum strain is small.

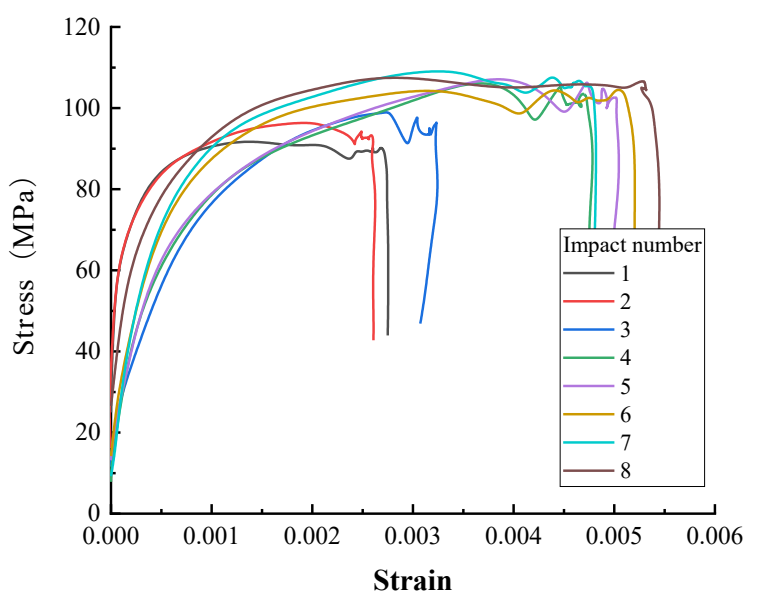

Fig. 6. Cyclic impact stress-strain curve under $0.09 \mathrm{MPa}$ impact air pressure

Damage nucleus formation stage: During the 3-5 impacts, after the large-size original cracks are compacted, the strength of the specimen increases slightly, and the original damage nuclei begins to form and increase rapidly, but the crack size is small, resulting in constant stress during the impact Elevated, there is no obvious constant stress stage.

Finally, the crack propagation and crack penetration stage: After the number of activated cracks quickly reaches the peak, the cracks rapidly expand and penetrate in the axial direction until the specimen is destroyed. The unloading effect caused by the opening of the crack makes the constant stress stage reappear.

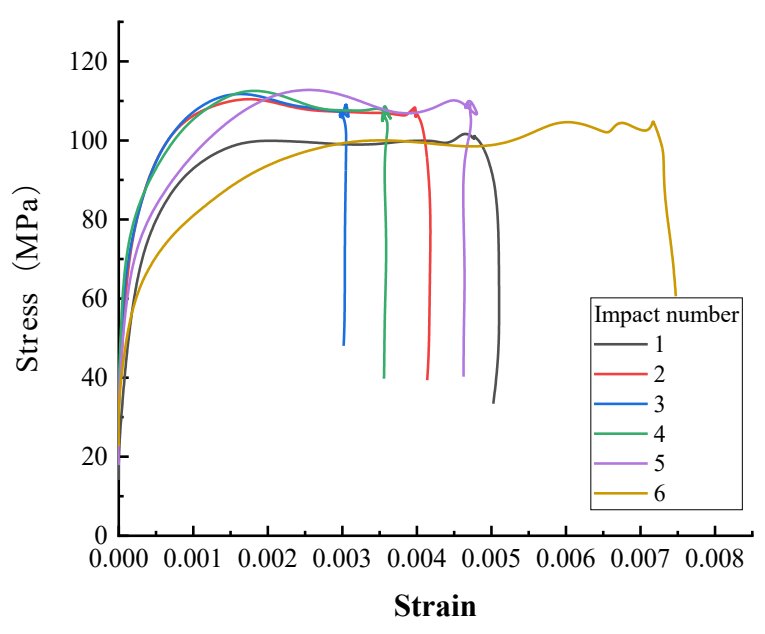

Fig. 7. Cyclic impact stress-strain curve under $0.12 \mathrm{MPa}$ impact air pressure

Fig.7 shows the stress-strain situation of the B1 specimen under the acceleration condition of $0.12 \mathrm{MPa}$. The trend dispersion of the curve is small. The strain of the first 
Nan Hu, Changhong Li, BODA Eric,Chen Qiao and Yonggang Xiao/

Journal of Engineering Science and Technology Review 14 (1) (2021) 107 - 113

impact and the last impact is larger, the maximum stress value is smaller, and other impact processes The curve overlap is higher, and the strain value increases steadily. It shows that the compaction effect is obvious during the initial impact, the stress value is smaller, and the strain value is larger. Due to the relatively large load, in the subsequent impact process, the nucleation and crack expansion in the specimen proceeded simultaneously, and there was no obvious differentiation. During the whole process, the constant stress stage of the curve is obvious. In the last impact, the crack penetrated rapidly, the maximum stress decreased, and the maximum strain increased significantly.

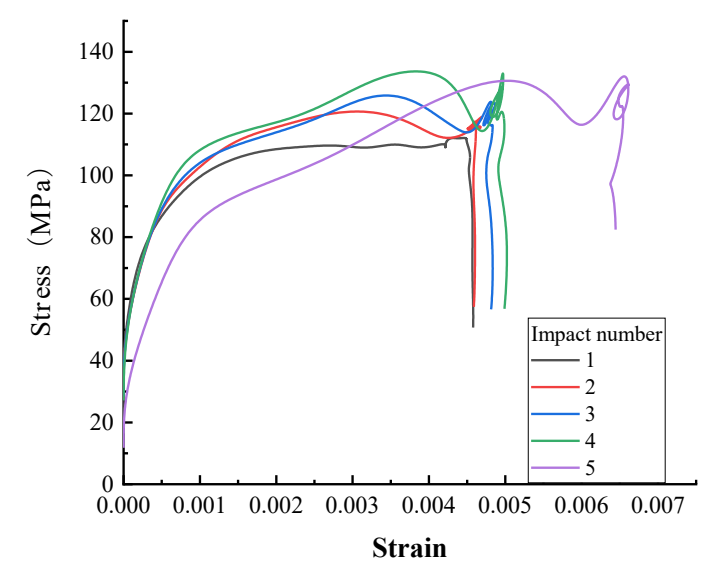

Fig. 8. Cyclic impact stress-strain curve under $0.16 \mathrm{MPa}$ impact air pressure

Fig. 8 shows the acceleration air pressure of $0.16 \mathrm{MPa}$, which generates a relatively large dynamic load, which is about $90 \%$ of the maximum impact load. Under this condition, the $\mathrm{C} 1$ specimen has an obvious constant stress stage during the first impact. From the second to the fourth impact, when the stress is around $110 \mathrm{MPa}$, the slope of the curve tends to decrease rapidly, followed by a secondary increase in stress. Due to the accumulation of damage in the specimen, the stress-strain curve of the fifth impact showed a larger peak strain, and the elastic modulus was also significantly reduced, but the maximum stress change was not obvious. The analysis believes that under a large impact load, the crack propagation and opening process cannot fully release the impact energy, causing the stress to rise again after a short unloading action.

A set of single impact failure tests are added for comparison and the typical stress-strain curve is shown in Fig. 9. Under the working condition of the impact air pressure of $0.2 \mathrm{MPa}$, the maximum stress of the single impact failure of the D1 specimen is $97.69612 \mathrm{MPa}$, which is close to the maximum stress of the first impact during the cyclic impact. After reaching the peak of the stress, there is no obvious constant stress stage, indicating that under the action of larger impact load, the internal micro-cracks of the test piece have not been fully developed, but quickly penetrated along the weak surface, causing the damage of the test piece.

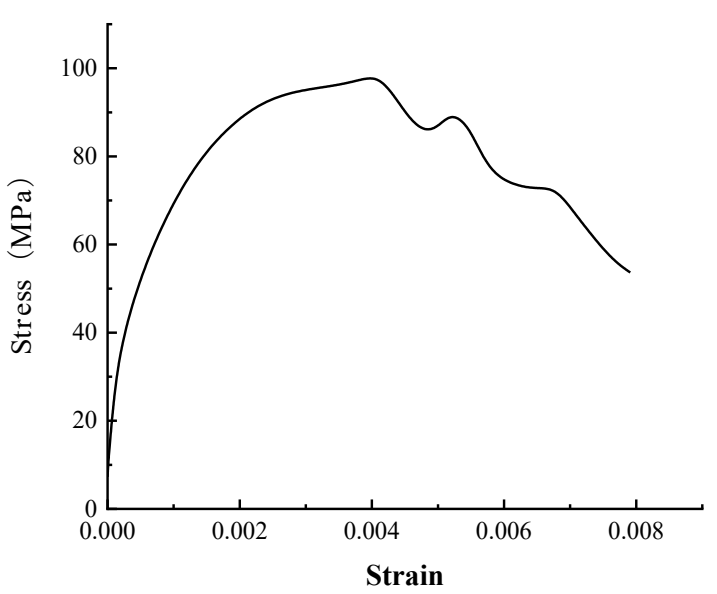

Fig. 9. Stress-strain curve of single impact failure under $0.20 \mathrm{MPa}$ impact air pressure

\subsection{Evolution characteristics of strain, strain and stress peak}

The maximum stress, maximum strain and maximum strain rate of the cyclic impact process can reflect the damage degree of the rock under impact from different angles, as shown in Table 1.

Table. 1. Peak strain rate, peak strain and peak stress

\begin{tabular}{|c|c|c|c|c|}
\hline $\begin{array}{l}\text { Accelera } \\
\text { tion } \\
\text { pressure } \\
/ \mathrm{MPa}\end{array}$ & $\begin{array}{c}\text { Numb } \\
\text { er of } \\
\text { impac } \\
\text { ts }\end{array}$ & $\begin{array}{c}\text { Peak } \\
\text { strain } \\
\text { rate } / \%\end{array}$ & $\begin{array}{c}\text { Peak } \\
\text { strain }\end{array}$ & Peak stress /MPa \\
\hline \multirow{8}{*}{0.09} & 1 & 71.43 & 0.00275 & 91.73 \\
\hline & 2 & 82.21 & 0.00263 & 96.34 \\
\hline & 3 & 89.17 & 0.00324 & 98.94 \\
\hline & 4 & 128.52 & 0.00478 & 106.09 \\
\hline & 5 & 134.00 & 0.00504 & 107.09 \\
\hline & 6 & 110.66 & 0.00520 & 104.48 \\
\hline & 7 & 115.98 & 0.00481 & 109.04 \\
\hline & 8 & 128.86 & 0.00544 & 107.46 \\
\hline \multirow{6}{*}{0.12} & 1 & 98.47 & 0.00510 & 101.63 \\
\hline & 2 & 94.55 & 0.00418 & 110.43 \\
\hline & 3 & 80.40 & 0.00308 & 111.74 \\
\hline & 4 & 101.23 & 0.00364 & 112.54 \\
\hline & 5 & 122.96 & 0.00480 & 112.77 \\
\hline & 6 & 145.96 & 0.00747 & 104.74 \\
\hline \multirow{5}{*}{0.16} & 1 & 100.91 & 0.0045 & 112.11 \\
\hline & 2 & 122.94 & 0.00469 & 120.66 \\
\hline & 3 & 131.08 & 0.00487 & 125.84 \\
\hline & 4 & 139.31 & 0.00502 & 133.65 \\
\hline & 5 & 185.79 & 0.00661 & 132.03 \\
\hline 0.2 & 1 & 132.56 & 0.00399 & 97.70 \\
\hline
\end{tabular}

During the cyclic impact process, with the increase of the number of impacts, the peak stress of the specimen under each working condition showed an increasing trend. This is mainly due to the irreversible compaction of the original cracks in the specimen under the impact load, which makes the rock more compact, which increases the impact strength of the rock. The internal cracks in the specimen are mainly caused by tensile action, and their development direction is mostly along the It is the axial direction of the impact force, so the impact strength of the rock in this direction is not obvious.

Under the action of different impact air pressure, with the increase of impact load, the maximum impact strength of rock increases. The average peak strength of the A1 specimen under the impact pressure of $0.09 \mathrm{MPa}$ is 
102.64MPa. The average value of the peak strength of the $\mathrm{B} 1$ specimen under the impact pressure of $0.12 \mathrm{MPa}$ is $105.98 \mathrm{MPa}$, and the average value of the peak strength of the $\mathrm{C} 1$ specimen under the impact pressure of $0.16 \mathrm{MPa}$. The average strength is $124.86 \mathrm{MPa}$. The D1 specimen is damaged by a single impact, and its peak strength is $97.70 \mathrm{MPa}$. It shows that during a single impact, the compaction effect is not obvious, and the specimen is quickly destroyed, which also reflects that compaction can increase the impact strength of granite within a certain range.

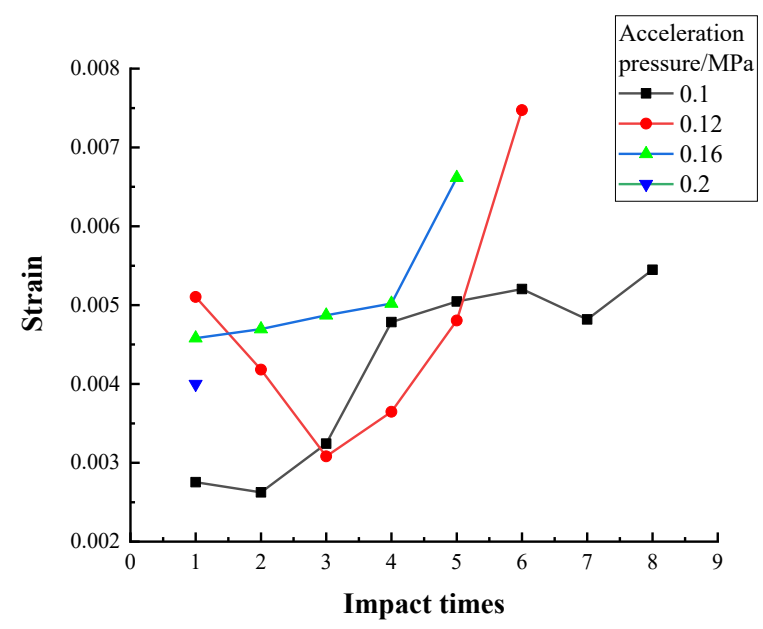

Fig. 10. Peak strain change during cyclic impact

The change rule of strain with the number of impacts during impact is shown in Figure 10. The peak strains of A1 and $\mathrm{C} 1$ specimens generally show an increasing trend with the increase of the number of impacts. Among them, the rising trend of the peak strain of the A1 specimen is unstable. The reason is that under the action of low-strength impact, the compaction effect of the crack and the expansion effect of the crack appear sequentially during the impact process. The peak strain during the first three impacts is low, which is manifested as compaction, but too small impact load is not enough to cause a large amount of collapse of the original void. The upward trend of the 5th-8th impact is slower, mainly due to the expansion of cracks. The $\mathrm{C} 1$ specimen received a relatively large impact load, which was about $90 \%$ of the impact load. The main reason for the increase in peak strain was the propagation of cracks. The slope of the steady rise of the peak strain is very similar to that of the A1 specimen in 5-8 shocks, which also proves this. The peak strain change trend of the B1 specimen shows an obvious trend of first decreasing and then increasing. Because compaction and crack propagation occur simultaneously during the punching process, and the initial compaction is obvious.

When the D1 specimen is subjected to a large impact load, its maximum strain is 0.00399 , which is lower than the first impact strain under $0.12 \mathrm{MPa}$ and $0.16 \mathrm{MPa}$ impact air pressure conditions. It also reflects that the cracks inside the specimen have not been fully developed when a single impact is damaged under a high load.

\section{Conclusions}

To investigate the damage characteristics and failure modes of polyporous granite during cyclic loading, the cyclic impact tests of granite specimens with different strengths were carried out using SHPB. The stress and strain characteristics of the specimen in the process of cyclic impact were analyzed. The damage process of the specimen was studied by the method of damage mechanics. The following conclusions could be drawn:

(1) During the low-accelerating air pressure cyclic impact of $0.09,0.12$, and $0.16 \mathrm{MPa}$, the number of impacts required for the destruction of granite decreases with the increase in accelerating air pressure. The damage process of granite in the process is mainly manifested by the compaction of the original cracks and the growth of new cracks. The lower impact pressure indicates more evident differentiation of the two processes.

(2) During the low-velocity impact process, the granite specimens mainly show tensile failure of axial cracks. The stress-strain curve has an evident constant stress stage, and the stress value is approximately $110 \mathrm{MPa}$. The microcracks of the porous rock at the low-velocity impact line of action are mainly caused by tension. The growth process of the axial crack requires the impact load to reach a specific threshold. The growth and opening process of the crack convert the impact energy into surface energy, resulting in a relatively stable stress at this stage.

(3) In the cyclic impact process of $0.16 \mathrm{MPa}$ higher acceleration air pressure, after reaching the constant stress value of $110 \mathrm{MPa}$, a secondary stress growth occurs. At this time, the axial expansion of the crack cannot fully absorb the impact energy, and the test piece stress increases again.

(4) In the process of cyclic impact, the peak stress of granite shows an increasing trend as the number of impacts increases, until the peak stress of the last impact decreases slightly. Compaction has a certain strengthening effect on the strength of the specimen. The expansion of the test piece has no evident influence on the axial impact resistance.

This study puts forward a new understanding of the damage caused by rectangular stress waves in porous granite, and the failure modes and failure characteristics are closer to the actual site. However, due to the lack of on-site macroscopic monitoring data, in future studies, combining the on-site mining stress monitoring results with existing models and modifying them improve the understanding of the destructive effects of cyclic shocks.

\section{Acknowledgements}

This work was supported by the National key technologies Research and Development program (2018YFC0808402) and the Fundamental Research Funds for the Central Universities (FRF-TP-20-004A2).

This is an Open Access article distributed under the terms of the Creative Commons Attribution License.

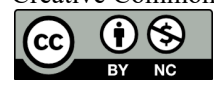

\section{References}

1. Su, S., "Analysis of mechanical properties of rock under cyclic impact load”. Sichuan Building Materials, 43(12) ,2017, pp.94-104. 
Nan Hu, Changhong Li, BODA Eric,Chen Qiao and Yonggang Xiao/

\section{Journal of Engineering Science and Technology Review 14 (1) (2021) 107 - 113}

2. Kaushik, D., V.M.S.R.Murthy, "Prediction of blast-induced overbreak from uncontrolled burn-cut blasting in tunnels driven through medium rock class".Tunneling and Underground Space Technology, 28(1) ,2012, pp.49-56.

3. Hao, H., Wu, C., Zhou, Y., "Numerical analysis of blast-induced stress waves in a rock mass with anisotropic continuum damage models,PartI:equivaient material property approach".Rock Mechanics and Rock Engineering, 35(2) ,2002, pp.79-94.

4. Eyal,S.,V,L., Audrey,O., Yariv,H., Zhu,W., "Inelastic compactio $\mathrm{n}$, dilation and hysteresis of sandstones under hydrostatic conditions ".Geophysical Journal International, 197(2) ,2014, pp. 920-925.

5. Ping, Q., Luo, X., Ma, Q.,Yuan, P., "Broken energy dissipation characteristics of sandstone specimens under impact loads". Chinese Journal of Rock Mechanics and Engineering, 34(S2), 2015,pp.41974203.

6. Liu, S., Xu J,, Wang P., Zhang,G., "Mechanical and ultrasonic analysis on damage of sandstone under cyclical impact loading with confining pressure". Journal of Vibration and Shock, 34(1), 2015, pp.190-194.

7. Meglis, I.L., Chow, T., Martin, C.D., Young, R.P., “Assessing in situ microcrack damage using ultrasonic velocity tomography". International Journal of Rock Mechanics and Mining, 42(1),2005, pp. 25-34.

8. Xu, Y., Dai, F., Xu, N.,Zhao, T., "Numerical investigation of dynamic rock fracture toughness determination using a semi-circular bend specimen in split Hopkinson pressure bar testing". Rock Mechanics and Rock Engineering, 49(3) ,2016, pp.731-745.

9. Li, X., Li, H. Liu, K.Zhang, Q.,Zou,F.,Huang,L.,Zhao,J., "Dynamic properties and fracture characteristics of rocks subject to impact loading". Chinese Journal of Rock Mechanics and Engineering, 36(10),2017, pp.2393-2405.

10. Gan, D.,Liu, Z.,Li, Z.,Gao,F.,Ren, H., "Broken energy dissipation characteristics of magnetite under impact loads". Chinese Journal of Rock Mechanics and Engineering, 37(S1), 2018,pp.3500-3506.

11. Liu, H., Li, J., Pei, X., “A dynamic damage constitutive model for $\mathrm{r}$ ock mass with intermittent joints ".Explosion and Shock Waves, 38(2) ,2018,pp.316-323.

12. Zhang, Z., Gao F., "Experimental research on energy evolution of $r$ ed sandstone samples under uniaxial compression ".Chinese Journal of Rock Mechanics and Engineering, 31(5) ,2012, pp. 953-962.
13. Zhang, F.,Guo, H., Zhao, J,.Hu, D.,Sheng, Q.,Shao,J., "Experimental study of micromechanical properties of granite". Chinese Journal of Rock Mechanics and Engineering, 36(2),2017,pp.3864-3872.

14. Lv, X., Xu, J., Ge H., Zhao, D.,Bai, E., "Effects of confining pressure on mechanical behaviors of sandstone under dynamic imapct loads". Chinese Journal of Rock Mechanics and Engineering, 29(01),2009, pp.193-201.

15. Gatelier, N., Pellet, F., "Mechanical damage of an anisotropic porous rock in cyclic triaxial tests". International Journal of Rock Mechanics and Mining, 39(3), 2002, pp.335-354.

16. Bagde, M. N., Petros, V., "Fatigue properties of intact sandstone samples subjected to dynamic uniaxial cyclical loading". International Journal of Rock Mechanics and Mining Sciences, 42(2), 2005, pp.237-250.

17. Gregoire, D., Maigre, H., Combescure, A., "New experimental and numerical techniques to study the arrest and the restart of a crack under impact in transparent materials". International Journal of Solids and Structures, 46(18-19) ,2009, pp.3480-3491.

18. Ravi-chandar, K.,Knauss, W. G., "An experimental investigation into dynamic fracture:I. Crack initiation and arrest". International Journal of Fracture, 25,1984, pp.247-262.

19. Ghamgosar, M.,Erarslan, N., "Experimental and numerical studies on development of fracture process zone(FPZ) in rocks under cyclic and static loadings". Rock Mechanics and Rock Engineering, 49(3),2016, pp.893-908.

20. Erarslan, N., Williamsd, J., "The damage mechanism of rock fatigue and its relationship to the fracture toughness of rocks". International Journal of Rock Mechanics and Mining Sciences, 56,2012, pp.15-26.

21. Erarslan, N. "“A Study on the evaluation of the fracture process zone in CCNBD rock samples". Experimental Mechanics, 53(8) ,2013, pp.1475-1489.

22. Malika, A., Chakrabortyb, T., Raob, K. S., "Strain rate effect on the mechanical behavior of basalt: Observations from static and dynamic tests". Thin-Walled Structures, 126(SI), 2018, pp.127-137.

23. Alam, M.S., Chakraborty, T., Matsagar, V., Matsagar. V., Rao, K. S., Sharma, P., Singh, M., "Characterization of kota sandstone under different strain rates in uniaxial loading". Geotechnical and Geological Engineering, 33(1), 2015, pp.143-152. 